\title{
Substrate-borne vibrations disrupt the mating behaviors of the neotropical brown stink bug, Euschistus heros: implications for pest management
}

\author{
R. A. Laumann' ${ }^{1}$ - D. H. B. Maccagnan ${ }^{2} \cdot$ A. Čokl ${ }^{3} \cdot$ M. C. Blassioli-Moraes ${ }^{1} \cdot$ M. Borges $^{1}$
}

Received: 24 October 2017 / Revised: 7 February 2018 / Accepted: 9 February 2018 / Published online: 20 February 2018

(c) Springer-Verlag GmbH Germany, part of Springer Nature 2018

\begin{abstract}
Stink bugs are key pests around the world. The principal method for managing these pests is the use of broad-spectrum insecticides. However, disrupting sexual communication could also be a biorational alternative for pest management. In this study, pure tone vibrations, mechanically transmitted to plants, were tested for their potential to disrupt the reproductive behavior of the neotropical brown stink bug, Euschistus heros. This species is one of the main pests in soybean production in Brazil. Three experimental procedures were developed using artificial pure tone vibrations $(20-200 \mathrm{~Hz})$, which were played back and mechanically transmitted to plants as background noise. In Test 1, the impact of pure tones on the emission of male and female vibratory signals was analyzed. In Test 2, reproductive behavior was monitored in the presence of background noise, and in Test 3, long-term effects ( $24 \mathrm{~h}$ ) of noise on reproductive success were evaluated. Results showed that pure tone vibrations of $75-200 \mathrm{~Hz}$ increased the proportion of females that spontaneously emitted signal while inhibiting the signaling and searching of males for females. It reduced copulation of $94.2-100 \%$ compared to control pairs. In long-term experiments, background noise delayed and slightly reduced mating frequency by $24.7 \%$. Females exposed to background noise had reduced fecundity and fertility. This study demonstrates the potential of mechanical vibrations as a mating-disrupting tactic for stink bug management.
\end{abstract}

Keywords Substrate-borne signals $\cdot$ Interference $\cdot$ Background noise $\cdot$ Animal communication $\cdot$ Biorational control

\section{Key message}

Communicated by D.C. Weber.

Electronic supplementary material The online version of this article (https://doi.org/10.1007/s10340-018-0961-5) contains supplementary material, which is available to authorized users.

R. A. Laumann

raul.laumann@embrapa.br

1 Embrapa Recursos Genéticos e Biotecnologia, PqEBAvda W5 (Norte) Final, Brasília, DF 71770-917, Brazil

2 Universidade Estadual de Goiás - Campus Iporá, Avda R2 Qd1, Iporá, GO 76200-000, Brazil

3 Department of Organisms and Ecosystems Research, National Instituteof Biology, Večna pot 111, 1000 Ljubljana, Slovenia
- The effect of background noise on substrate-borne vibratory communication, mating, and copulation of the brown stink bug $E$. heros was investigated.

- Abiotic noise disrupts insect communication.

- Frequencies of 75-200 Hz reduced communication and copulation of this stink bug and also female fecundity and fertility.

- Interference noise is a potential mating disruption strategy for biorational management of stink bugs.

\section{Introduction}

Because of their polyphagous feeding habits and wide geographic distribution, stink bugs (Hemiptera: Pentatomidae) are major pests around the world, feeding on legumes, grains, grasses, vegetables, fruits, and nut trees 
(Panizzi et al. 2000). Some species, such as Halyomorpha halys (Stål), Bagrada hilaris (Burmeister), and Piezodorus guildinii (Westwood), are invasive into new continents and have the potential to become damaging pests for many crops (Panizzi 2015).

The principal and most effective short-term control method for these pests is still the application of broad-spectrum insecticides. However, this has a consequent impact on the environment and human health. In the soybean production systems of Brazil, the use of insecticides to control stink bugs has increased threefold to fivefold in recent years (Panizzi 2013). Therefore, the investigation of alternative methods is needed to develop efficient, environmentally friendly control techniques to decrease and replace the use of insecticides.

Interference in insect communication using substrateborne vibratory signals has been considered an alternative method for pest management (Mankin 2012). Vibratory signals have the potential to be used as a repellent, mating disruption strategy and for population monitoring (Mankin 2012; Polajnar et al. 2015; Mazzoni et al. 2017a; Laumann et al. 2017).

Communication between mates plays a crucial role in reproductive behavior. The interruption of communication represents a potential effective method for disrupting mating and decreasing target species populations because of the species-specific nature of information exchange between mates. The use of sex pheromones for lepidopteran pest control is the most well-known case of mating disruption in insects. This is an efficient method of pest control that has been extended to wide areas around the world (Witzgall et al. 2010).

The potential for using substrate vibrations as a mating disruption strategy has been shown in some species of Cicadellidae (Saxena and Kumar 1980; Mazzoni et al. 2009, 2017b; Eriksson et al. 2012; Polajnar et al. 2016; Gordon et al. 2017) and also in the Delphacidae, Nilaparva talugens (Stål) (Saxena and Kumar 1980) and in Diaphorina citri (Liviidae) (Lujo et al. 2016).

Plant-dwelling stink bugs communicate during reproductive behaviors predominantly by chemical (Borges and Blassioli-Moraes 2017) and substrate-borne vibratory signals (Čokl et al. 2017a). Sexual communication starts with male emission of pheromones that attract females to the same plant (Borges et al. 1987). On the plant, females attract males by the emission of vibratory signals with calling function (Čokl et al. 2017a). These steps of reproductive behavior are characterized as the calling phase by Borges et al. (1987), which triggers male responses characterized by the emission of the calling signals during the search for the female. Duetting with calling signals changes at close distances to the mutual emission of the courtship signals and touching, which both lead to copulation (Čokl et al. 2017a).
Competition of several males for copulation with the same female leads to alternating male rival signaling that silences the calling female and rival males (Čokl et al. 2017a).

The interference with stink bug communication using chemical or vibratory signals may be effective during the calling phase of mating behaviors, although interference during the courtship phase should not be discounted (Čokl et al. 2017b; Laumann et al. 2017).

Abiotic or biotic noise could interfere with the vibratory communication of stink bugs (Virant-Doberlet et al. 2014). Pure tone vibrations of $100 \mathrm{~Hz}$ inhibited the orientation toward females in Nezara viridula (L.) males and significantly reduced the emission of calling and courtship signals. In females, the $100-\mathrm{Hz}$ noise induced changes in the rhythm of the calling signal and, in some of them, stimulated the emission of a repelling signal (Polajnar and Čokl 2008). Similar responses were observed in the presence of biotic noise. $N$. viridula males reduced their signaling activity and did not start searching for the female when they were simultaneously stimulated with conspecific or heterospecific female calling signals (Miklas et al. 2003) or natural and synthesized conspecific female calling signals with altered frequencies and temporal parameters (de Groot et al. 2010; Žunič et al. 2011). In contrast, Spezia et al. (2008) showed that white noise improved the communication of $N$. viridula males on artificial dummy plants because signals at levels below the threshold of the insect's detection (subthreshold) were amplified by stochastic resonance phenomena.

To prevent noise interference, females change the dominant frequency of their calls to differentiate them from the 100-Hz disturbance noise (Polajnar and Čokl 2008). Such a reaction has also been described in Euschistus heros (Fabr.) (Čokl et al. 2015). Males and females of these species change the frequency and temporal characteristics of their overlapped signals to advertise themselves and to minimize or avoid the effects of noise interference (Polajnar and Čokl 2008; Čokl et al. 2015).

To our knowledge, there is no information regarding vibratory interference on reproductive success (i.e., copulation rate, fecundity, and fertility) of stink bugs. To fill this gap, we tested the effect of pure tone vibrations mechanically transmitted to plants on the reproductive behavior of the brown stink bug, E. heros. Our hypothesis was that pure tone vibrations with similar frequencies to those emitted by $E$. heros will reduce the number of successful copulations by disrupting communication during reproductive behavior. The results of our study provide a basis for the development of an effective and targeted strategy for stink bug biorational control. 


\section{Materials and methods}

\section{Experimental animals and plants}

E. heros adults were obtained from a colony started with individuals collected, between December 2015 and March 2016, from soybean fields near Brasília, DF, Brazil $\left(15^{\circ} 47^{\prime} 37^{\prime \prime} \mathrm{S} ; 47^{\circ} 52^{\prime} 57^{\prime \prime} \mathrm{W}\right)$. Insects were maintained in an environmentally controlled room $\left(26 \pm 1{ }^{\circ} \mathrm{C}, 60 \pm 10 \%\right.$ RH, 14:10 h L:D photoperiod under four 40-W fluorescent light) in plastic cages of $26 \mathrm{~cm}$ in height and $22 \mathrm{~cm}$ in diameter. Bugs were fed bean pods (Phaseolus vulgaris L.) and seeds of peanuts (Arachis hypogaea L.), soybean (Glycine max L.) and sunflower (Helianthus annuus L.). For all tests, sexually mature (10 days after adult molt) virgin males and females were used. Each male or female was tested only once.

All experiments were carried out on soybean plants with two opposite trifoliate leaves potted in soil in plastic pots $20 \mathrm{~cm}$ in height and $15 \mathrm{~cm}$ in width. Plants were replaced with new ones after their use in three to five bioassays (Figure 1, Supplementary material).

\section{Playback of pure tone background noise waveforms}

Pure tone background vibratory noises of 20,75, 100, 125, 150, or $200 \mathrm{~Hz}$ were synthesized using Sound Forge 6.0 software (Sonic Foundry Inc., Madison, WI, U.S.A.). To do this, a simple synthesis tool in the software was used to choose the frequency selected, which was composed of a sine waveform shape with an amplitude similar to those of the stink bug emissions (varying between -14 and $-20 \mathrm{~dB}$ ). The test plant was mechanically vibrated by the tip of an insect steel pin $(38 \mathrm{~mm} \times 0.5 \mathrm{~mm}$ in diameter $)$ fixed firmly to an electrodynamic vibrating exciter (minishaker 4810, Bruel \& Kjaer, Naerum, Denmark). The pin tip was attached to the stem of the soybean plant about $5 \mathrm{~cm}$ above the soil (see the complete setup in Figure 2 of Supplementary material). The velocity of pure tone background noise was adjusted to the values measured for naturally emitted signals on soybean plants $(0.5-1 \mathrm{~mm} / \mathrm{s})$. Experiments were conducted in a sound-insulated room with pots placed on a shockproof table to reduce environmental noise.

Vibrations of plants induced by bugs and/or background noise were recorded by a laser vibrometer (PDV-100, Polytec, Waldbronn, Germany). The beam of the vibrometer was directed perpendicularly to the stem about $10 \mathrm{~cm}$ above the soil and $5 \mathrm{~cm}$ above the vibration point. To improve reflection, a small piece of reflective tape was glued on the recording point. Registered signals were amplified and digitized via an USB audio capture sound card (UA-25EX, Edirol-Roland, 24 bits-96 kHz, RolandCorp, Japan) and stored on a computer using Cool Edit Pro 2.0 software (Adobe Systems Inc., San Jose, CA, U.S.A.) at a sample rate of $44.1-\mathrm{kHz}$ mono and resolution of the 16 bit (Figure 2, Supplementary material).

\section{Experimental procedures}

To evaluate the effect of background noise on E. heros reproductive behavior, communication and copulation success were determined using three types of tests. In Test 1 , the impact of pure tones on the emission of male and female vibratory signals was analyzed. In Test 2 , reproductive behavior was monitored in the presence of background noise, and in Test 3, the long-term effects of background noise on reproductive success were analyzed.

\section{Test 1}

In this test, a single insect (male or female) was placed on the test plant. After the male or the female stopped moving, a 6-min test began. During the first $5 \mathrm{~min}$, one of the background noise frequencies vibrated the plants, and we subsequently observed the behavior of insects on the nonvibrated plant for $1 \mathrm{~min}$. Control tests were conducted on non-vibrated plants under the same conditions for a total of $6 \mathrm{~min}$. In each test, the emission of different types of female or male vibratory signals (classified by Moraes et al. 2005) was assessed. The number of individuals that emitted at least one signal during vibration with the background noise and during the total duration of the test was monitored and quantified. The latency time (i.e., the time between the start of the test and the emission of the first signal) was also measured. Twenty insects of each sex were evaluated in each background noise frequency condition and in the control condition.

\section{Test 2}

In this experiment, a male and a female were placed on opposite leaves of the test plant. After the individuals stopped moving, a 20-min test was conducted, which consisted of 10 min of background noise emissions using the setup previously described, followed by $10 \mathrm{~min}$ without background noise. Forty mating pairs were evaluated at each background noise frequency and in the control conditions (no vibration emissions during the 20 -min test). The number of pairs that copulated and the time spent in different phases of the mating behavior were registered, including the time needed to start searching by males, the duration of male searching (i.e., oriented movements of females), and the courtship times. Searching and courtship were defined 
according to the definition by Borges et al. (1987): Searching is oriented movements of males toward females, and courtship is the behaviors developed when the insects are in physical contact (beginning of courtship) until the beginning of copulation (end of courtship).

\section{Test 3}

In this test, the setup involved two plants in contact via leaves that allowed the free movement of insects and the transmission of vibrational signals from one plant to another. One male was placed on one plant and one female on the other plant. Pots with plants stood on a glass plate $(122 \times 68 \times 0.5 \mathrm{~cm})$ supported by a metal bench. The plants vibrated continuously for $24 \mathrm{~h}$ with a $125-\mathrm{Hz}$ pure tone background noise using a loudspeaker $(10 \mathrm{~cm}$ in diameter, low-midrange loudspeaker, 40-6000-Hz frequency response, impedance $8 \Omega$, Radioshack, Taiwan) that contacted the glass plate. The pure tone signals were played using the same software described above. The $125-\mathrm{Hz}$ pure tone signals were selected because this frequency is the most similar to the dominant frequency emitted by E. heros, and they showed similar levels of inhibition compared to other frequencies between 75 and $200 \mathrm{~Hz}$ (see Results). The vibration of the plants induced by the stink bugs and/or background noise was monitored by a laser vibrometer as previously described. All of the plants in the setup were monitored to check for background noise prior to the beginning of the experiment. This setup efficiently transmitted background noise to all plants in the test (Figure 3, Supplementary material).

The experiment started at 8 a.m., and in the first $12 \mathrm{~h}$, we recorded the number of pairs that copulated every $15 \mathrm{~min}$ and the place on the plants where copulation occurred. As most of the pairs copulated during the first $7 \mathrm{~h}$ of the experiment (see Results) during the second $12 \mathrm{~h}$, insects were observed at 3- to 4-h intervals. These observation intervals were established from previous observations of reproductive behavior in stink bugs. In artificial arenas and plant experiments, pairs of virgin insects typically start copulation after 10-20 min (Moraes et al. 2005; Kavčič et al. 2013; Čok1 et al. 2015) and copulation in E. heros could extend overnight (Costa et al. 1998). Control experiments were conducted under the same conditions and protocol with nonvibrated plants.

Twenty-five replicates were performed on two consecutive days ( $n=12$ and 13, respectively) for the treatment and control conditions. Replicates in which one or both insects in the pair moved away from the plants $(n=3$ in control plants and $n=7$ in treatment plants) were not included in the data analyses.

We recorded the time required to start copulation (i.e., time since the beginning of the experiment) until a specific pair was observed in copulation. We assayed copulation at 1-h intervals during the first $12 \mathrm{~h}$ of the experiment and during the 12- to 24-h period in the second half of the experiment.

After $24 \mathrm{~h}$ of the test, insects were removed from the plants. Females were cultured individually in $250-\mathrm{mL}$ plastic pots and fed and maintained under the same conditions described previously. Oviposition by females was monitored daily until the female died, and fecundity was calculated as the mean number of eggs per female. Each egg mass for each female was individualized and transferred to Petri dishes $(9 \mathrm{~cm}$ in diameter) and maintained until nymphs hatched in order to calculate fertility (number of nymphs/number of eggs). During this phase, insects were not exposed to any additional vibrations.

\section{Data analysis}

The proportion of males and females that emitted signals in the presence of noise (different pure tone vibrations) during all experimental time periods in Test 1 were compared with those of the control conditions using a two-proportion $Z$ test with continuity corrections. Latency times (the time between start of the experiment and the emission of the first signal) of females and males in the treatment and control conditions were compared using the Kruskal-Wallis test followed by Dunn's method for multiple comparisons between two groups. The number of signals emitted in Test 1 was compared between treatments (different pure tone vibrations) and the control condition (without noise) using generalized linear models (GLM) and deviance analyses (ANODEV) with Poisson errors and contrast analyses.

The rate of reproductive success was determined in Test 2 based upon the proportion of copulated pairs in vibrated (different pure tone vibrations) and non-vibrated (control) conditions for each treatment (background noise frequency) using a two-proportion $Z$ test. The mean duration of different behaviors measured in Test 2 was compared between the treatment conditions and control condition using the Kruskal-Wallis test followed by Dunn's method.

In Test 3, the proportion of pairs that copulated in the treatment versus control conditions were compared using a two-proportion $Z$ test. The time to start copulation was compared using the Mann-Whitney $U$ test. The locations where the pairs copulated were compared in each treatment using the Chi-square test. Fecundity (the number of deposited eggs/female) was compared using GLM analysis with Poisson errors and fertility (the number of nymphs/ number of eggs/female) with GLM analysis with a binomial distribution.

All tests were performed using the $\mathrm{R}$ platform, version 3.3.2 (R Development Core Team 2009) at $\alpha=0.05$. In GLM analyses when over-dispersion of data was observed quasilikelihood models were used. For multiple comparisons in 
the two proportion $Z$ tests the significance level were corrected using a one-step Bonferroni procedure (corrected significance level $\alpha=0.008$ ).

\section{Results}

\section{Test 1}

The $20-\mathrm{Hz}$ pure tone vibration had no influence on male or female signal emission. The vibration of the plant in the frequency range of 75-200 Hz had different effects on males and females. These vibrations inhibited male signaling and stimulated female signaling (Table 1). The playback of background emission frequencies of $75-200 \mathrm{~Hz}$ influenced the proportion of males that emitted at least one signal per test, which varied from 0.1 to 0.5 . In contrast, in control or $20-\mathrm{Hz}$ vibration conditions, most of the males emitted at least one signal per test (Table 1, see complete analyses results in Supplementary material 5). The proportion of females emitting at least one signal per test varied from 0.7 to 1 under vibrations of $75-200 \mathrm{~Hz}$. This value was 0.4 in control conditions and 0.3 when the plant was vibrated with a $20-\mathrm{Hz}$ pure tone noise (Table 1 and Supplementary material 5). The emission of vibratory signals by males under the influence of background vibrations of $75-200 \mathrm{~Hz}$ was delayed compared with the insects signaling in control or the $20-\mathrm{Hz}$ vibration conditions (Kruskal-Wallis test $\chi_{6}^{2}=47.41, P=1.55 \times 10^{-8}$, and Dunn's test $P=0.05$ ). In contrast to the males, females emitted their first signals after a significantly shorter delay following the start of the $75-200-\mathrm{Hz}$ vibration stimulation compared with the $20-\mathrm{Hz}$ vibration condition or the control condition (Kruskal-Wallis test $\chi_{6}^{2}=40.58, P=3.52 \times 10^{-7}$, and Dunn's test $P=0.05$ ) (Table 1).

The opposite effect of plant vibrations on male and female signaling using the $75-200-\mathrm{Hz}$ noise was also clear when comparing the number of signals emitted per stink bug. Males and females predominantly emitted the calling signal (MS1 and FS1) (Moraes et al. 2005), and the number of their emissions decreased in males and increased in females (deviance analyses, $F_{6,133}=16.74 P=2.80 \times 10^{-7}$ for MS1 and $F_{6,133}=23.89, P=2.2 \times 10^{-16}$ for FS1) in relation to the control conditions (Fig. 1).

\section{Test 2}

Proportion analysis revealed a significant reduction in the mating success of $E$. heros pairs in the presence of continuous plant vibrations consisting of pure tones of $75-200 \mathrm{~Hz}$ when compared to control conditions (Fig. 2). Pure tone plant vibrations in the frequency range of $75-200 \mathrm{~Hz}$ significantly decreased the proportion of mated pairs (Fig. 2). During the first half of the experiment, $85 \%$ of pairs copulated in the control condition and $73 \%$ of pairs copulated in the $20-\mathrm{Hz}$ vibration conditions (Fig. 2). Considering the total duration of the test $(20 \mathrm{~min})$, pairs of all treatments showed similar mating frequencies, ranging from 78 to $85 \%$ (Fig. 2). Plant vibrations with $75-200-\mathrm{Hz}$ pure tones significantly delayed males from starting to search for females (Kruskal-Wallis test $\chi_{6}^{2}=125.39, P=1.20 \times 10^{-24}$ ) (Fig. 3). In most cases, searching behavior started almost immediately after the background noise was switched off. Searching $(378.09 \pm 69.91 \mathrm{~s}$, mean of treatments $\pm \mathrm{SD}$, range $300-492.76 \mathrm{~s})$ and courting $(256.70 \pm 24.89 \mathrm{~s}$, mean of treatments $\pm \mathrm{SD}$, range $224.07-289.20 \mathrm{~s}$ ) times were not
Table 1 Number of individuals and proportion, in parentheses, of the total observed ( $n=20$ per treatment) that emitted at least one signal under the influence of pure tone background noise (BN) (300 s), number of individuals and proportion of the total observed that emit- ted at least one signal during full experiment $(F)$ (360 s), and latency time (mean $\pm \mathrm{SD}$ ) of males and females of Euschistus heros when tested in the presence and absence of different frequencies background noise continuously transmitted to soybean plants

\begin{tabular}{|c|c|c|c|c|c|c|}
\hline \multirow{2}{*}{$\begin{array}{l}\text { Backgorund noise } \\
(\mathrm{Hz})\end{array}$} & \multicolumn{3}{|l|}{ Male } & \multicolumn{3}{|l|}{ Female } \\
\hline & $\mathrm{BN}$ & $F$ & Latency time (s) & $\mathrm{BN}$ & $F$ & Latency time (s) \\
\hline Control & $19(0.95)$ & $19(0.95)$ & $31.7 \pm 30.88 \mathrm{a}$ & $8(0.4)$ & $17(0.85)$ & $128.9 \pm 90.2 \mathrm{a}$ \\
\hline 20 & $18(0.85) \mathrm{ns}$ & $20(1)$ & $70.3 \pm 103.52 \mathrm{a}$ & $6(0.3) \mathrm{ns}$ & $13(0.65)$ & $203.8 \pm 126.3 \mathrm{a}$ \\
\hline 75 & $2(0.1)^{*}$ & $19(0.95)$ & $295.2 \pm 46.54 \mathrm{~b}$ & $14(0.7)^{*}$ & $14(0.7)$ & $58.9 \pm 60.1 \mathrm{~b}$ \\
\hline 100 & $8(0.4)^{*}$ & $17(0.85)$ & $228.8 \pm 111.09 \mathrm{~b}$ & $19(0.95)^{*}$ & $20(1)$ & $41.5 \pm 67.3 b c$ \\
\hline 125 & $10(0.5)^{*}$ & $20(1)$ & $196.6 \pm 130.49 b$ & $20(1)^{*}$ & $20(1)$ & $20.2 \pm 17.8 \mathrm{c}$ \\
\hline 150 & $8(0.4)^{*}$ & $19(0.95)$ & $220.1 \pm 119.16 b$ & $20(1)^{*}$ & $20(1)$ & $44.2 \pm 51.1 \mathrm{bc}$ \\
\hline 200 & $7(0.35)^{*}$ & $16(0.80)$ & $205.7 \pm 137.31 b$ & $20(1)^{*}$ & $20(1)$ & $31.9 \pm 31.9 \mathrm{bc}$ \\
\hline
\end{tabular}

ns: nonsignificant differences in proportions of males or females signaling on a plant under the influence of background noise (continuous pure tone signals) in relation to proportion of individuals signaling in control (without background noise) conditions

$*$ Significant differences in proportions ( $Z$ test for proportion, $\alpha=0.008$ after Bonferroni corrections). For $F$ (full experiment) nonsignificant differences were found in all comparisons. Mean latency times followed by similar letters in each column are not significantly different (KruskalWallis and Dunn's tests $P<0.05$ ) 

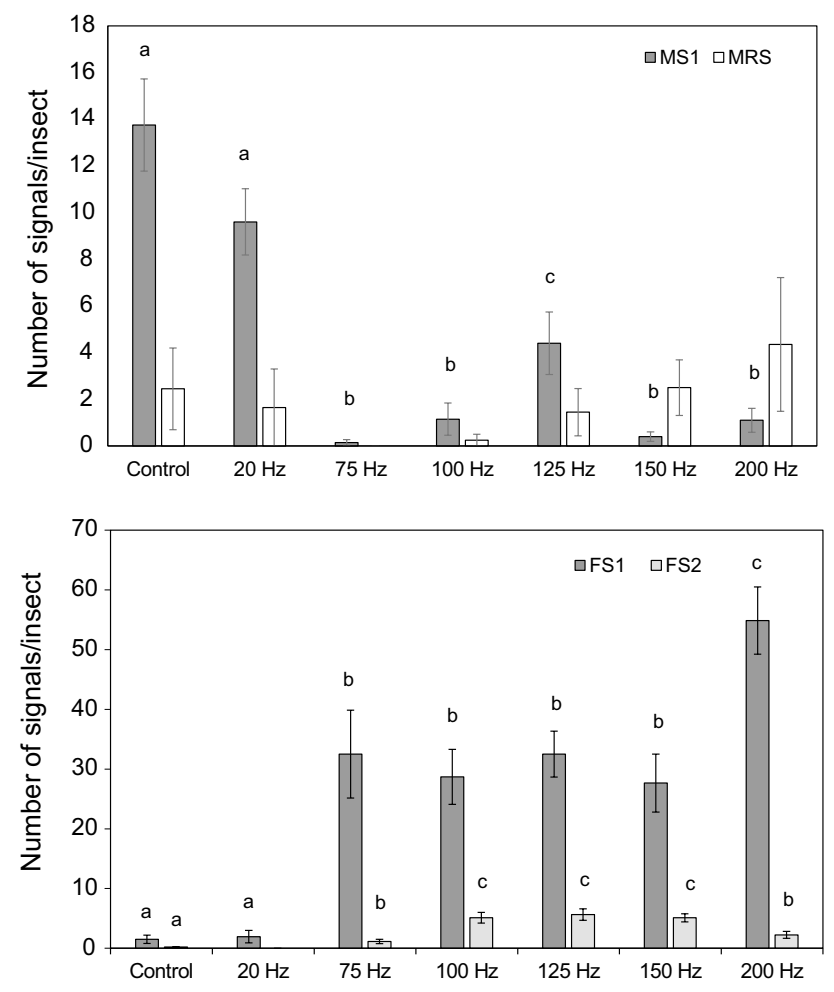

Fig. 1 Interference effect of pure tone frequencies in the vibratory signals emission of males (upper graph) and females (lower graph) of Euschistus heros. Bars indicate mean number of signals emitted by each individual during pure tone frequencies emission ( \pm SD). MS1: males signal 1, MRS: male rivalry signal, FS1: female signal 1 and FS2: females signal 2. Signal nomenclature follows Moraes et al. (2005). Bars with same letters indicate nonsignificant differences between mean number of signals of each type (ANODEV and contrast analyses $P>0.05$ )

significantly different between the control and plant vibration conditions (Kruskal-Wallis test: for searching time: $\chi_{6}^{2}=7.41, P=0.285$ and for courting time: $\chi_{6}^{2}=6.14$, $P=0.408)$.

\section{Test 3}

The background noise (pure tone vibrations of $125 \mathrm{~Hz}$ ) significantly delayed the initiation of copulation (Wilcoxon test, $W=378 d f=38, P=1.046 \times 10^{-6}$ ) (Fig. 4). In control conditions, $100 \%$ of the mates copulated in the first $7 \mathrm{~h}$ of the experiment. In contrast, only $50 \%$ of vibrated mates copulated during the first $7 \mathrm{~h}$ of the experiment and after $24 \mathrm{~h}$, only $77.3 \%$ of them had copulated (which represents a reduction of $22.7 \%$ in relation to control conditions). However, we observed no significant differences between the treatment and control conditions $\left(Z\right.$ test, $\chi_{1}^{2}=3.40$, $P=0.065)$ when comparing the total percentage of pairs that mated during the duration of the experiment $(24 \mathrm{~h})$ (Fig. 4). In control conditions, most pairs copulated on

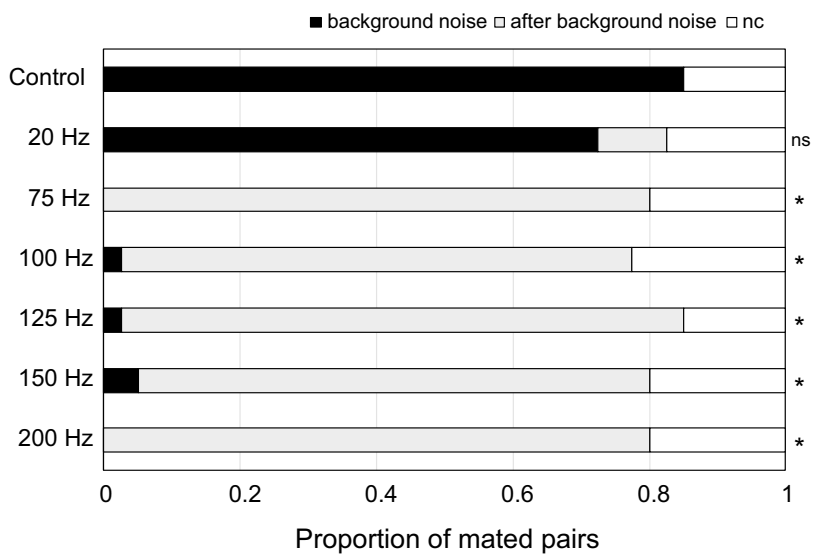

Fig. 2 Proportion of observed pairs that mated during $10 \mathrm{~min}$ of pure tone frequencies emission (black bars, background noise), $10 \mathrm{~min}$ after the interruption of emission of pure tone frequencies (gray bars, after background noise), or that do not copulate (white bars, $\mathrm{nc}) . \mathrm{ns}=$ nonsignificant and $*=$ significant differences in proportion of pair that mated during the experimental phase when background noise was reproduced in relation to pairs in control plants ( $Z$ test $P=0.008$, significance level was corrected by one-step Bonferroni procedure). Total proportion of insects that copulate considering the total experimental time did not show statistical differences between different treatment and control conditions ( $Z$ test $P=0.008$, significance level was corrected by one-step Bonferroni procedure)

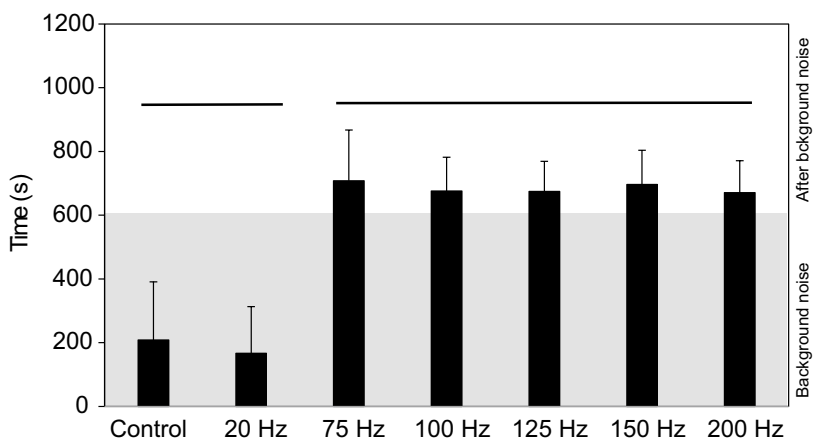

Fig. 3 Euschistus heros male search latency (time to start searching) (mean $\pm \mathrm{SD}$ ) in experiments with continuous background noise created by waveforms of pure tones of different frequencies. Gray area represents phase of the experiment when the background noise was played back. Horizontal lines above the bars joint treatments where the means did not show significant differences (Kruskal-Wallis and Dunn's test $P<0.05$ )

the plants on which females were released $\left(\chi_{1}^{2}=6.54\right.$, $P=0.01)$ at the start of the experiment. In contrast, in the treatment conditions, no significant differences were observed in the location of copulation $\left(\chi_{1}^{2}=2.0, P=0.16\right)$, but a greater number of couples were observed on the plants where the males had been released (Fig. 5).

Treatment with $125-\mathrm{Hz}$ vibratory background noise reduced the fecundity (GLM quasi-Poisson, $t=2.03$, 

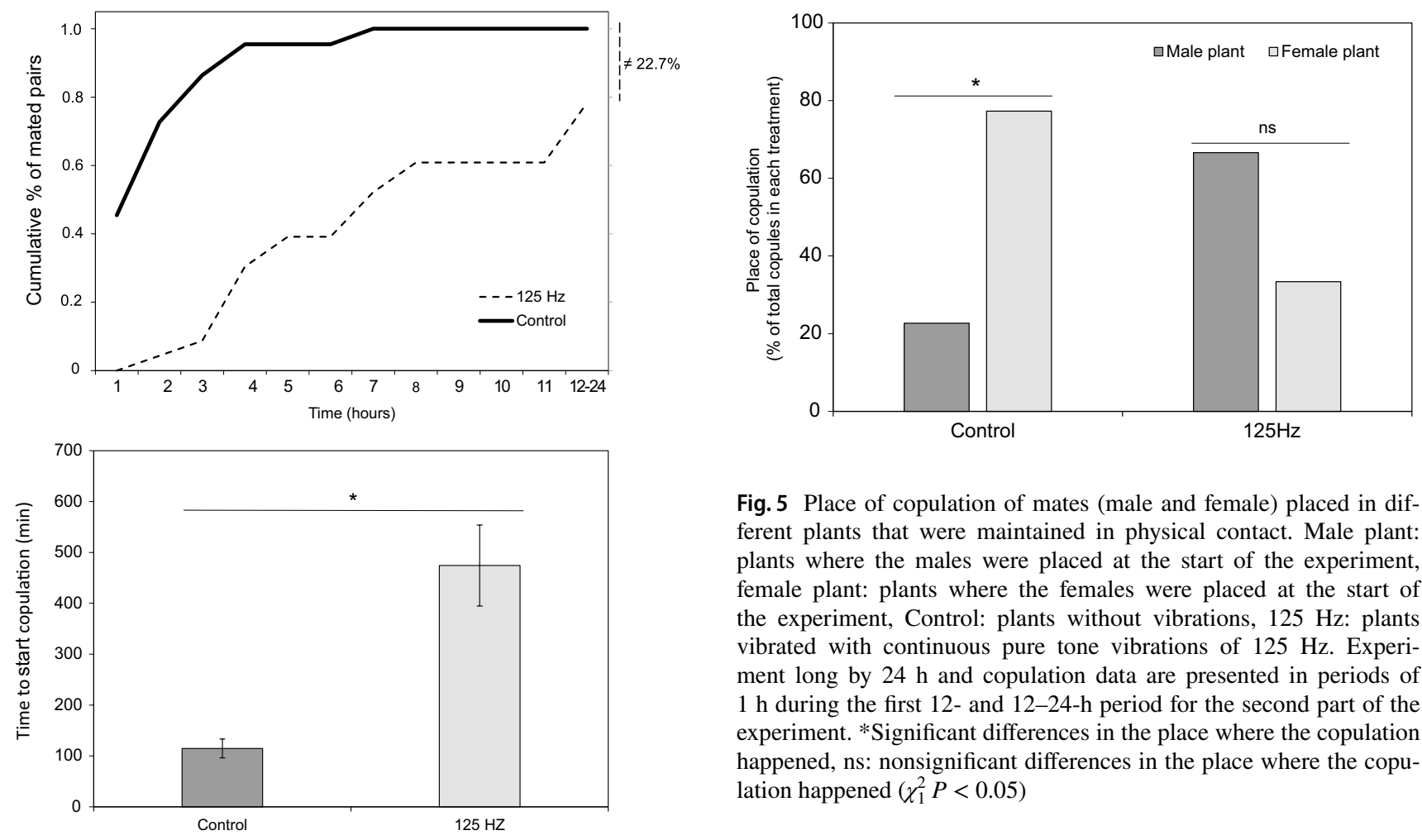

Fig. 5 Place of copulation of mates (male and female) placed in different plants that were maintained in physical contact. Male plant: plants where the males were placed at the start of the experiment, female plant: plants where the females were placed at the start of the experiment, Control: plants without vibrations, $125 \mathrm{~Hz}$ : plants vibrated with continuous pure tone vibrations of $125 \mathrm{~Hz}$. Experiment long by $24 \mathrm{~h}$ and copulation data are presented in periods of $1 \mathrm{~h}$ during the first 12- and 12-24-h period for the second part of the experiment. *Significant differences in the place where the copulation happened, ns: nonsignificant differences in the place where the copulation happened $\left(\chi_{1}^{2} P<0.05\right)$

Fig. 4 Cumulative \% of copulations of observed mates (upper graph) and mean time $( \pm$ SD) to start copulation (lower graph) of mates (male and female) placed in different plants that were maintained in physical contact. Control: plants without vibrations, $125 \mathrm{~Hz}$ : plants vibrated with continuous pure tone vibrations of $125 \mathrm{~Hz}$. *Significant differences in mean time between control and $125-\mathrm{Hz}$ treatments (GLM analyses $P<0.05$ )

$P=0.048, d f=44)$ and fertility (GLM quasi-binomial, $t=2.48, P=0.017, d f=44$ ) of females (Fig. 6).

\section{Discussion}

The results of the present study show a disrupting effect of pure tone vibration background noise on the reproductive behavior of stink bugs. The disrupting effect was observed when soybean plants were vibrated in the frequency range characteristic of the stink bug signals (Čokl et al. 2017a).

Pure tone vibration background noise of $75-200 \mathrm{~Hz}$ induced female calling. In contrast, males showed clear inhibition in their calling and searching for females. Males of E. heros and others species of stink bugs (Zgonik and Čokl 2014) signal spontaneously more often than females do in the absence of plant vibrations. The increase in the emission of female calling signals in the presence of background noise could have been a direct effect of these vibrations. In fact, it has been demonstrated that vibratory, visual, and chemical

signals trigger calling emissions in female green stink bugs, N. viridula (Zgonik and Čokl 2014).

The background noise also significantly reduced mating behaviors and copulation. One reason for this effect may have been the disruption of vibrational directionality of male movement to calling females, which is generated by processing the amplitude and time differences between sensory inputs on spatially positioned legs on the plant branches (Čokl et al. 1999). The interference of spectrally similar, naturally emitted signals and pure tone noise may disable this process and prevent the localization of females.

A similar effect has been shown in $N$. viridula males. In this species, a $100-\mathrm{Hz}$ vibratory noise disturbance reduced the number of males searching for females; on the other hand, this had no influence on the time needed to reach the signal source (Polajnar and Čokl 2008). In N. viridula males, searching and orientation were also negatively affected in experiments involving simultaneous playback of female calling signals of conspecific and alien species, which overlapped and changed species-specific temporal patterns of the conspecific signal (de Groot et al. 2010). This disrupting effect on the males' orientation observed in E. heros and $N$. viridula appears to be efficient only when background noise is in the narrow frequency range characteristic of stink bug communication signals. White noise amplified, by stochastic resonance, $N$. viridula females' signals and enabled communication even when signals were at subthreshold levels (Spezia et al. 2008). 

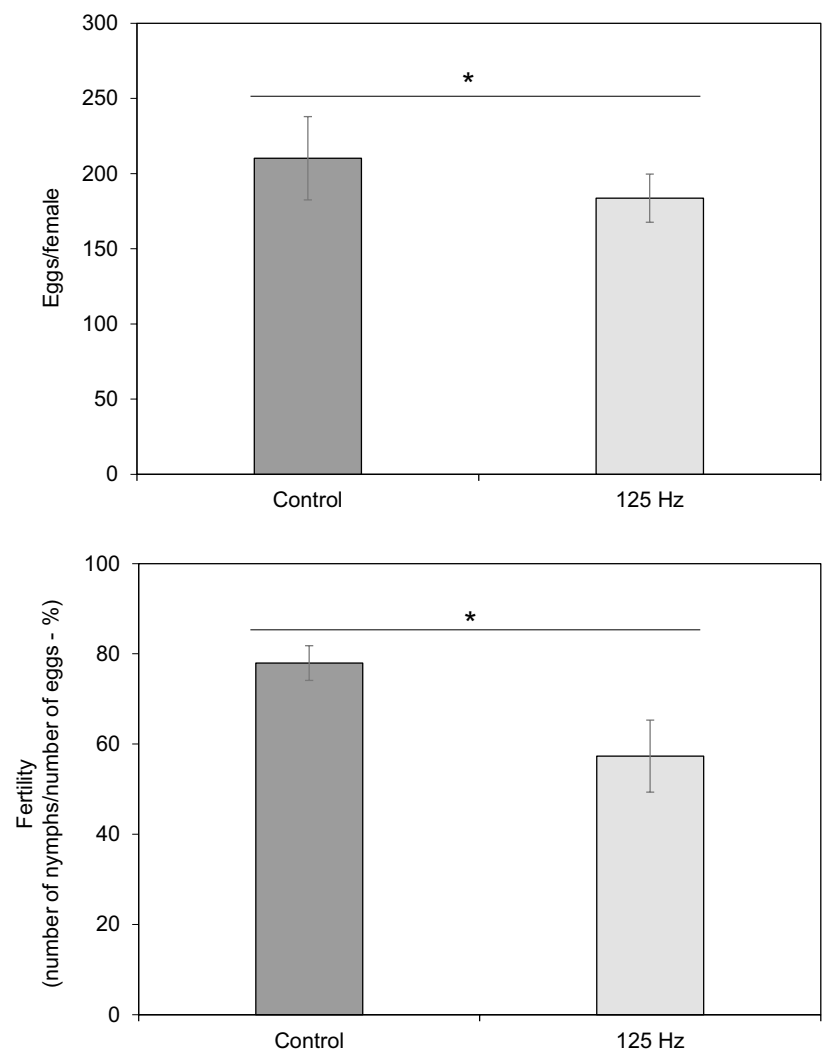

Fig. 6 Fecundity (mean number of eggs/female \pm SD) (upper graph) and fertility (mean number of nymphs/number of eggs in $\% \pm \mathrm{SD}$ ) (lower graph) of females from 24-h experiments (Test 3) after exposed to $125-\mathrm{Hz}$ vibrations for $24 \mathrm{~h}$ and maintained without additional vibrations until dead. Control: plants without vibrations, $125 \mathrm{~Hz}$ : plants vibrated with continuous pure tone vibrations of $125 \mathrm{~Hz}$. *Significant differences in fecundity and fertility of females of each treatment (GLM analyses $P<0.05$ )

Long-term experiments conducted in Test 3 delayed mating, but did not completely disrupt it. We can explain this effect by habituation phenomena and pheromone production.

Habituation to environmental noise has been well documented in insects (Mankin 2012). Different mechanisms reduce the effect of interference caused by overlapping noise (Brumm and Slabbekoorn 2005; Greenfield 1994). Stink bugs increase this frequency difference by shifting the dominant frequency of their calls away from the dominant frequency of the disturbance vibration, which was reported to occur in N. viridula (Polajnar and Čokl 2008; Polajnar et al. 2016) and E. heros (Čokl et al. 2015). This frequency shift was also observed in our experiments when plants were vibrated with frequencies similar to the dominant signal frequency of the species $(75-150 \mathrm{~Hz})$ (Supplementary material 3 and 4), and this appears to be the principal mechanism for avoiding noise interference.

The other hypothesis is related to the increased amounts of sex pheromones produced by males released on vibrated plants. In the presence of background noise, no significant differences were observed in the location of copulation, but a greater number of couples were observed on the plants where the males had been released, suggesting that the female movement to males might be a consequence of pheromone-based attraction. This could be the result of the stimulation of females to emit calling signals by the background noise as described previously, which, in turn, may have stimulated males to increase their pheromone release. This hypothesis is supported by experimental data showing that male $E$. heros commonly produced pheromones daily (Zhang et al. 2003; Blassioli-Moraes et al. 2008). In addition, it is known that in $N$. viridula males, pheromone production is stimulated by female vibratory signals (Miklas et al. 2003; Zgonik and Čokl 2014). The effect of females and artificial signals on male pheromone production in $E$. heros has not been investigated yet. However, the studies in $N$. viridula suggest that this hypothesis is plausible and could explain the results observed in our 24-h experiments.

The effect of background noise on E. heros female fecundity and fertility requires additional investigation to determine the underlying mechanisms. The $125-\mathrm{Hz}$ background noise could stress the mating pairs, reducing the copulation times and/or decreasing the efficiency of sperm transfer. No information is available regarding direct or indirect effects of noise on different phases of copulation, so this hypothesis remains to be tested.

Although several studies demonstrate the disruption of airborne and substrate-borne vibratory communication by noise (Brumm and Slabbekoorn 2005; Slabbekoorn and Peet 2003; Virant-Doberlet et al. 2014), only a few discuss the applications of these results as a possible method for controlling insect pests.

Saxena and Kumar (1980) first reported on the use of vibratory signals for pest control. In the cotton leafhopper, Amrasca devastans (Dist.) (Hemiptera: Cicadellidae), and the rice brown planthopper, $N$. lugens, stimulation by airborne signals picked up by the host plants interrupted their sexual behaviors for at least $4 \mathrm{~h}$ (Saxena and Kumar 1980). The potential of substrate vibration for the control of the vineyard pest Scaphoideus titanus Ball (Hemiptera: Cicadellidae) (Mazzoni et al. 2009; Eriksson et al. 2012; Polajnar et al. 2016) and in the Asian citrus psyllid, D. citri (Lujo et al. 2016) was also demonstrated in the laboratory and in semi-field and field tests with copulation reduction similar to those observed in E. heros. Using an approach similar to our study, Mazzoni et al. (2017b) earlier showed that synthetic vibrations consisting of $80-\mathrm{Hz}$ pure tone frequencies suppressed male signaling to females in the glassy-winged sharpshooter, Homalodisca vitripennis (Germar) (Hemiptera: Cicadellidae). This was observed even when the disruptive vibration was played back at $10 \mathrm{~dB}$ below the normal female signals. In addition, it was demonstrated that white 
noise and continuously overlapping female signals played back to mating pairs significantly reduced mating rates and stimulated females to signal (Gordon et al. 2017).

All of these studies showed the disrupting effects of background noise in insect vibratory communication; however, the underlying mechanism is not yet understood The comprehension of this mechanism could be relevant to a wide use of disrupting vibrations in pest control.

Specifically for stink bugs, it could help to understand the habituation effects when frequencies are applied for a long time period. Probably, habituation could be reduced by discontinuous reproduction in a temporal pattern similar to that of stink bug signals. Another possibility could be the use of heterospecific signals as background noise, including those of predators, male rival signals, female repellent signals, and male signals emitted prior to copulation. All of these signals have disruptive effects on stink bug communication, which could be used to stop male or female signal emissions (Čokl et al. 2017b). In addition, some of these signals are attractive to natural enemies as egg parasitoids (Laumann et al. 2007, 2011), so signals could be used also for their behavior manipulation aiming increasing biological control.

Another problem relates to signal amplitude. In this work, we used signal amplitudes that were characteristic of normal stink bug emissions. However, signals with higher or lower amplitudes can have different effects (Mazzoni et al. 2014, 2017b; Polajnar et al. 2014).

Stink bugs are considered to be major crop pests around the world, and, because of their adaptive plasticity, many species are invasive in different growing regions of the globe. The results presented here could help to develop a tool for a strategy of biorational management. However, the use of vibrations for mating disruption of stink bugs appears to be a possibility that demands deeper knowledge, particularly the development of a mechanism for vibration transmission in the field.

\section{Author contributions}

RAL, DHBM, MCBM, MB, and AC conceived and designed research. DHBM and RAL conducted experiments and data analyses. RAL, DHBM, MCBM, MB, and AC wrote and approved the manuscript.

\footnotetext{
Acknowledgements We are grateful to Aline Moreira Dias and Samantha da Silveira for their help with insect rearing. We are also grateful to two anonymous reviewers who helped to improve the quality of this manuscript.
}

Funding The National Council for Scientific and Technological Development (CNPq) supports M Borges, MCB Moraes, and R Laumann with productivity grants. This work was supported by the Research Support Foundation of the Federal District (FAP-DF, Project
193.000.978/2015) and the Slovenian National Research Agency (Research Program No. P1-0255).

\section{Compliance with ethical standards}

Conflict of interest Authors declare that they have no conflict of interest.

Ethical approval This article does not contain any studies with human participants. All applicable international, national, and/or institutional guidelines for the care and use of animals were followed.

\section{References}

Blassioli-Moraes MC, Pareja M, Laumann RA, Borges M (2008) The chemical volatiles (Semiochemicals) produced by neotropical stink bugs (Hemiptera: Pentatomidae). Neotrop Entomol 37:489-505. https://doi.org/10.1590/S1519-566X200800 0500001

Borges M, Blassioli-Moraes MC (2017) The semiochemistry of Pentatomidae. In: Čokl A, Borges M (eds) Stink bugs: biorational control based on communication processes, 1st edn. CRC Press, Boca Raton, pp 95-124

Borges M, Jepson PC, Howse PE (1987) Long-range mate location and close-range courtship behavior of the green stink bug, Nezara viridula and its mediation by sex pheromone. Entomol Exp Appl 44:205-212. https://doi.org/10.1111/j.1570-7458.1987.tb00546.x

Brumm H, Slabbekoorn H (2005) Acoustic communication in noise. Adv Stud Behav 35:151-209. https://doi.org/10.1016/S0065 $-3454(05) 35004-2$

Čokl A, Virant-Doberlet M, McDowell A (1999) Vibrational directionality in the southern green stink bug, Nezara viridula (L.), is mediated by female signal. An Behav 58:1277-1283. https:// doi.org/10.1006/anbe.1999.1272

Čokl A, Laumann RA, Žunič-Kosi A, Blassioli-Moraes MC, VirantDoberlet M, Borges M (2015) Interference of overlapping insect vibratory communication signals: an Euschistus heros model. PLoS ONE 10:1-16. https://doi.org/10.1371/journ al.pone. 0130775

Čokl A, Laumann RA, Stritih N (2017a) Substrate-borne vibratory communication. In: Čokl A, Borges M (eds) Stink bugs: biorational control based on communication processes, 1st edn. CRC Press, Boca Raton, pp 125-164

Čokl A, Blassioli-Moraes MC, Laumann RA, Borges M, Communication as the basis for biorational control (2017b) In: Čokl A, Borges M (eds) Stink bugs: biorational control based on communication processes, 1st edn. CRC Press, Boca Raton, pp 78-94

Costa MLM, Borges M, Vilela EF (1998) Biologia reprodutiva de Euschistus heros (F.) (Heteroptera: Pentatomidae). An Soc Entomol Bras 27:559-568

de Groot M, Čokl A, Virant-Doberlet M (2010) Effects of heterospecific and conspecific vibrational signal overlap and signal-to noise ratio on male responsiveness in Nezara viridula (L.). J Exp Biol 213:3213-3222. https://doi.org/10.1242/jeb.044024

Eriksson A, Anfora G, Lucchi A, Lanzo F, Virant-Doberlet M, Mazzon V (2012) Exploitation of insect vibrational signals reveals a new method of pest management. PLoS ONE 7:1-5. https:// doi.org/10.1371/journal.pone.0032954

Gordon SD, Sandoval N, Mazzoni V, Krugner R (2017) Mating interference of glassy-winged sharpshooters, Homalodisca vitripennis. Entomol Exp Appl 164:27-34. https://doi.org/10.1111/eea.12594 
Greenfield MD (1994) Synchronous and alternating choruses in insects and anurans: common mechanisms and diverse functions. Am Zool 34:605-615

Kavčič A, Čokl A, Laumann RA, Moraes-Blassioli MC, Borges M (2013) Tremulatory and abdômen vibration signals enable communication through air in the stink bug Euschistus heros. PLoS ONE 8:1-10. https://doi.org/10.1371/journal.pone.0056503

Laumann RA, Moraes MCB, Čokl A, Borges M (2007) Eavesdropping on the sexual vibratory communication of stink bugs (Hemiptera: Pentatomidae) by the egg parasitoid Telenomuspodisi. Anim Behav 73:637-649. https://doi.org/10.1016/j.anbehav.2006.09.011

Laumann RA, Čokl A, Lopes APS, Ferreira JBC, Moraes MCB, Borges M (2011) Silent singers are not safe: selective response of a parasitoid to substrate-borne vibratory signals of stink bugs. Anim Behav 82:1175-1183. https://doi.org/10.1016/j.anbeh av.2006.09.011

Laumann RA, Maccaganan DHB, Čokl A (2017) Use of vibratory signals for stink bug monitoring and control. In: Čokl A, Borges M (eds) Stink bugs: biorational control based on communication processes, 1st edn. CRC Press, Boca Raton, pp 226-245

Lujo S, Hartman E, Norton K, Pregmon EA, Rohde BB, Mankin RW (2016) Disrupting mating behavior of Diaphorina citri (Liviidae). J Econ Entomol 109:2373-2379. https://doi.org/10.1093/ jee/tow 202

Mankin RW (2012) Applications of acoustics in insect pest management. CAB Rev 7:1-7. https://doi.org/10.1079/PAVSNNR201 27001

Mazzoni V, Lucchi A, Čokl A, Prešern J, Virant-Doberlet M (2009) Disruption of the reproductive behavior of Scaphoideus titanus by playback of vibrational signals. Entomol Exp Appl 133:174-185. https://doi.org/10.1111/j.1570-7458.2009.00911.x

Mazzoni V, Eriksson A, Anfora G, Lucchi A, Virant-Doberlet M (2014) Active space and role of amplitude in plant-borne vibrational communication. In: Cocroft RB, Gogala M, Hill PSM, Wessel A (eds) Studying vibrational communication, 1st edn. Springer, Berlin, pp 125-145

Mazzoni V, Polajnar J, Baldini M, Rossi Stacconi V, Anfora G, Giuidetti R, Maistrello L (2017a) Use of substrate-borne vibrational signals to attract the brown marmorated stink bug, Halyomorp hahalys. J Pest Sci 90:1219-1229. https://doi.org/10.1007/s1034 0-017-0862-z

Mazzoni V, Gordon SD, Nieria R, Krugnerb R (2017b) Design of a candidate vibrational signal for mating disruption against the glassy-winged sharpshooter, Homalodisca vitripennis. Pest Manag Sci 73:2328-2333. https://doi.org/10.1002/ps.4619

Miklas N, Lasnier T, Renou M (2003) Male bugs modulate pheromone emission in response to vibratory signals of the conspecifics. J Chem Ecol 29:561-574. https://doi.org/10.1023/A:1022898620 429

Moraes MCB, Laumann RA, Čokl A, Borges M (2005) Vibratory signals of four Neotropical stink bug species. Physiol Entomol 30:175-188. https://doi.org/10.1111/j.1365-3032.2005.00446.x

Panizzi AR (2013) History and contemporary perspectives of the integrated pest management of soybean in Brazil. Neotrop Entomol 42:119-127. https://doi.org/10.1007/s13744-013-0111-y

Panizzi AR (2015) Growing problems with stink bugs (Hemiptera: Heteroptera: Pentatomidae): species invasive to the U.S. and potential neotropical invaders. Am Entomol 61:223-233. https:// doi.org/10.1093/ae/tmv068

Panizzi AR, McPherson JE, James DG, Javahery M, McPherson RM (2000) Economic importance of stink bugs (Pentatomidae). In: Schaefer CW, Panizzi AR (eds) Heteroptera of economic importance, 1st edn. CRC Press, Boca Raton, pp 421-474

Polajnar J, Čokl A (2008) The effect of vibratory disturbance on sexual behavior of the southern green stink bug Nezara viridula (Heteroptera, Pentatomidae). Cent Eur J Biol 3:189-197. https://doi. org/10.2478/s11535-008-0008-7

Polajnar J, Eriksson A, Rossi Stacconi MV, Lucchi A, Anfora G, Virant-Doberlet M, Mazzoni V (2014) The process of pair formation mediated by substrate-borne vibrations in a small insect. Behav Process 107:68-78. https://doi.org/10.1016/j.bepro c. 2014.07.013

Polajnar J, Eriksson A, Lucchi A, Anfora G, Virant-Doberletc M, Mazzoni V (2015) Manipulating behavior with substrate-borne vibrations-potential for insect pest control. Pest Manag Sci 71:15-23. https://doi.org/10.1002/ps.3848

Polajnar J, Eriksson A, Lucchi A, Virant-Doberlet M, Mazzoni V (2016) Mating disruption of a grapevine pest using mechanical vibrations: from laboratory to the field. J Pest Sci 89:909-921. https://doi.org/10.1007/s10340-015-0726-3

R Development Core Team (2009) R: a language and environment for statistical computing. R Foundation for Statistical Computing, Vienna, Austria. ISBN 3-900051-07-0. http://www.R-project.org

Saxena KN, Kumar H (1980) Interruption of acoustic communication and mating in a leafhopper and a planthopper by aerial sound vibrations picked up by plants. Experientia 36:933-936

Slabbekoorn H, Peet M (2003) Birds sing at a higher pitch in urban noise. Nature 424:267. https://doi.org/10.1038/424267a

Spezia S, Curcio L, Fiasconaro A, Pizzolato N, Valenti D, Spagnolo B (2008) Evidence of stochastic resonance in the mating behavior of Nezara viridula (L.). Eur Phys J B 65:452-458. https://doi. org/10.1140/epjb/e2008-00333-4

Virant-Doberlet M, Mazzoni V, de Groot M, Polajnar J, Lucchi A, Symondson WOC, Čokl A (2014) Vibrational communication in networks: eavesdropping and biotic noise. In: Cocroft RB, Gogala M, Hill PSM, Wessel A (eds) Studying vibrational communication, animal signals and communication, vol 3. Springer, Berlin, pp 93-123

Witzgall P, Kirsch P, Cork A (2010) Sex pheromone and their impact on pest management. J Chem Ecol 36:80-100. https://doi. org/10.1007/s10886-009-9737-y

Zgonik V, Čokl A (2014) The role of signals of different modalities in initiating vibratory communication in Nezara viridula. Cent Eur J Biol 9:200-2011. https://doi.org/10.2478/s11535-013-0253-2

Zhang AM, Borges M, Aldrich JR, Camp M (2003) Stimulatory male volatiles for the Neotropical brown stink bug, Euschistus heros (F.) (Heteroptera: Pentatomidae). Neotrop Entomol 32:713-717. https://doi.org/10.1590/S1519-566X2003000400025

Žunič A, Virant-Doberlet M, Čokl A (2011) Species recognition during substrate-borne communication in Nezara viridula (L.) (Pentatomidae: Heteroptera). J Insect Behav 24:468-487. https://doi. org/10.1007/s10905-011-9272-x 